\title{
Do Trading Rules Based upon Winners and Losers Work Across Markets? Evidence from the Pacific Basin and U.S. Markets*
}

\author{
Hung-Gay Fung \\ University of Missouri, U.S.A. \\ Wai K. Leung \\ University of Hong Kong, Hong Kong \\ Gary A. Patterson \\ University of South Florida, U.S.A.
}

\begin{abstract}
Numerous studies have examined trading strategies that seek to exploit price reversal behaviors in the U.S. stock market. The evidence to date suggests that taking a long position in U.S. stocks with negative returns (losers) and a short position in stocks that have positive returns (winners) may yield large profits. This article expands this line of research by applying these trading rules to Pacific Basin markets. Striking differences in the pattern of portfolio returns between most Pacific Basin markets and those in the U.S. market are found. This article demonstrates that profitable trading strategies developed in the U.S. may not be successfully transferred to other national markets (JEL C1, F3, and G1).
\end{abstract}

Key words: Pacific Basin and U.S. stock markets, trading rules, transaction costs.

\section{Introduction}

Researchers have focused much attention on trading strategies that attempt to exploit predictable patterns of equity returns. The theoretical basis for many of these studies is DeBondt and Thaler's (1985)

\footnotetext{
*We would like to thank Peter Theodossiou (managing editor), the editor-in-charge, and three anonymous reviewers for useful comments, and Patricia Peat for excellent editorial help.

(Multinational Finance Journal, 1999, vol. 3, no. 1, pp. 41-70)

CMultinational Finance Society, a nonprofit corporation. All rights reserved. DOI: 10.17578/3-1-3
} 
overreaction hypothesis where investors overreact to good or bad news. In this model, large returns will be followed by significant returns of the opposite sign as investors overcompensate for earlier price movements. In the lagged return literature, some empirical studies find evidence of return reversals using short-horizon returns. Lehmann (1990) and Lo and MacKinlay $(1988,1990)$ document an apparent overreaction among investors of U.S. equities. A trading strategy that seeks to exploit such investor behavior is to buy stocks with negative returns (losers) and to short stocks with positive returns (winners) in a single period. This contrarian rule is based on the expectation that price reversals will occur in both loser and winner stocks.

Other studies, often with longer horizons, suggest that investors may underreact to unexpected information, and that a momentum strategy may produce excess profits. These studies include Brown, Harlow, and Tinic (1988), who propose the uncertain information hypothesis, Bernard and Thomas (1990), who study the post-earnings announcement drift, and Chan, Jegadeesh, and Lakonishok (1996), who link lagged returns to other fundamental variables. A trading strategy that exploits return momentum should incorporate a buy-and-hold strategy, particularly when past stock prices increase. Overall, studies using both short-and long-term horizons suggest that U.S. stock returns contain important information that can be used to forecast future stock returns.

Are trading strategies that produce large returns in the U.S. market as effective in Pacific Basin markets? Market fundamentals derived from analysis of the U.S. market may not apply in the case of other countries. Thus, we explore the patterns of predictability in non-U.S. stock markets by using a number of contrarian rules to examine profit opportunities in the Pacific Basin stock markets and compare patterns of return behavior to those in the U.S. stock market. Several studies have demonstrated that stock returns in Pacific Basin markets have strong autocorrelations. Thus, lagged returns in these equity markets may provide important information for future price movements. Bailey, Stulz, and Yen (1990) and Lo et al.(1993) also suggest that stock prices in Pacific Basin countries are slow to respond to economic information. With smaller markets, stock price movements may be susceptible to manipulations by a large player and by the infusion or withdrawal of foreign portfolio funds. As a result, these Pacific markets may offer profitable opportunities if appropriate trading strategies are implemented that exploit patterns that may or may not be similar with those of U.S. markets. 
Theoretical and empirical studies have also explored the relation between returns and trading volume to determine if information from these two variables may be used to better explain future stock returns. Blume, Easley, and O'Hara (1994) present a model demonstrating how investors may profit by incorporating historical price and volume information into their trading activities. Additionally, Campbell, Grossman, and Wang (1993) suggest that price changes in high-volume periods tend to be reversed, but that reversals may be less pervasive during periods of low trading volume. These theoretical papers are supported by the findings of Conrad, Hameed, and Niden (1994), who use contrarian trading rules in their study of Nasdaq stocks.

Although U.S.-based contrarian strategies appear to produce large profits, Rouwenhorst (1998) observes different return behavior in European markets, which appear to respond more to momentum trading strategies. ${ }^{1}$ Studies also show that the behavior of returns are affected by microstructure issues as well as government intervention, two areas where the Asian markets are quite different from the U.S. markets. ${ }^{2}$

This article applies several trading rules to the stock returns of the Pacific, NYSE, and AME stock markets and follows the tradition of earlier studies of U.S. equity markets by Conrad, Hameed, and Niden (1994), among others. It compares stock return behavior in the Pacific Basin markets, which have become more important in global financial markets, with those in the U.S. market. This article tests for evidence of market overreaction or a momentum effect among Pacific Basin equity securities by estimating daily returns based on a filter-rule designed to boost the signal-to-noise ratio in the security selection process. The portfolio construction process incorporates critical features of DeBondt and Thaler's overreaction hypothesis. We address an important characteristic of the hypothesis by taking either a long- or short-position in a security based upon the direction of its price movement. Importantly, we include a security in the portfolios only when the filter levels are exceeded. This approach to portfolio construction enables us to tap into any nonlinearity of investor overreaction where extreme lagged returns are more likely to identify profitable securities.

This article finds significant differences in the behavior of portfolio returns between the Pacific Basin and U.S. stock markets. The findings (1995)

1. These findings support earlier observations by Grinblatt, Titman, and Wermers

2. See Lo et al.(1993) and Rhee and Chang (1992). 
from the Pacific Basin markets are frequently supportive of a momentum effect, while the results from the U.S. markets support DeBondt and Thaler's original hypothesis. Interestingly, the findings reveal a strong, asymmetrical pattern of return behavior between winner and loser stocks in Asian markets. Winner portfolios in Pacific Basin markets exhibit strong patterns of positive autocovariance, while reversals occur among loser stocks. This article also shows that our findings prove robust across different holding periods as well as across different price filters, thus mitigating any bias that may occur from a bid-ask bounce. Importantly, this article shows that successful trading strategies in U.S. markets may not be readily transferred to Pacific Basin markets.

Consistent with studies of U.S. equities, we find that trading volume provides additional information to the portfolio construction process in all Asian markets. Additionally, a nonlinear returns-based trading rule and a returns size-based rule are shown to enhance profit opportunities in these markets. The inclusion of transaction costs eliminates most of the profits in our study, particularly if a contrarian trading strategy is used in Pacific Basin markets. A strategy relying upon a simple momentum strategy maintains a small level of profitability within the Asian markets when transaction costs are included.

The remainder of this article proceeds as follows: Section II presents the methodology and data, Section III discusses the findings, and Section IV provides the conclusions.

\section{Methodology and Data}

This article uses daily return and volume data on individual securities in the U.S. and six Asian markets. The U.S. data come from the NYSE CRSP tape. The Pacific Basin stock market data are obtained from the University of Rhode Island, PACAP database. The six Pacific Basin stock markets are Hong Kong, Japan, Korea, Malaysia, Taiwan, and Thailand. The study covers the 1980-1993 period. The daily return series are well-behaved for all countries, though the number of stocks varies substantially with Japan and the U.S. markets being considerably larger than the other markets. ${ }^{3}$ In our methodology, we use several variations of a returns-based strategy that employs different weighting

3. These results are available on request from the authors. 
schemes. Other methodologies that we employ include the use of trading volume in constructing portfolio weights. We also conduct tests for robustness to demonstrate the stability of our results.

\section{A. Returns-Based Strategy}

To analyze stock returns from different national markets for evidence of market reaction, we implement the portfolio construction procedure of Conrad, Hameed, and Niden (1994) to derive the weights in choosing winner $(W)$ and loser $(L)$ securities. We compare several contrarian weighting rules in this study. First, the portfolio weight given to a security $i$ at time $t$ is:

$$
w_{i, t}=\frac{R_{i, t-1}}{\sum_{i=1}^{N p} R_{i, t-1}}, \quad p=W, L,
$$

where $N_{p}$ is the number of securities in the winner and loser portfolio. In this strategy, a winner security has a positive return, while loser securities have negative returns.

The denominator in equation (1) sums only positive returns for the winner securities and negative returns for the loser securities where the weights in each winner or loser portfolio sum to one. All the weights in each winner or loser portfolio are positive, implying a positive investment in these securities. When we group the winner and loser securities in a combined portfolio, a net zero investment is maintained by buying the losers and shorting the winners.

\section{B. Returns Volume-Based Strategy}

While earlier studies of investor overreaction emphasize only stock returns, recent studies suggest that important information may be found in trading volume. Blume, Easley, and O'Hara (1994) suggest that investors may profit from a technical analysis of trading volume data. Additionally, Campbell, Grossman, and Wang (1993) suggest that trading volume may provide information to predict future stock returns.

To examine if trading activity is related to the return behavior on other exchanges, we categorize stocks into "high" and "low" volume categories. We define the high- and low-volume stock $i$ at time $t$ as: 


$$
v_{i, t}=\frac{s_{i, t}-s_{i, t-1}}{s_{i, t-1}},
$$

where $S_{i, t}$ is the number of shares traded in security $i$ for the day. A positive $v_{i, t-1}$ implies a positive trading shock or high-volume security, while a negative $v_{i, t-1}$ represents a low-volume security.

The returns volume-based weighting scheme incorporates the information from trading volume in formulating the portfolio rule as:

$$
w_{i, p, t}^{\prime}=\frac{\left(R_{i, t-1}\left(1+v_{i, t-1}\right)\right)}{\sum_{i=1}^{N p} R_{i, t-1}\left(v_{i, t-1}\right)}
$$

where $N_{p}$ is the number of securities in each winner $\left(R_{i, t-1}>0\right)$ or loser $\left(R_{i, t-1}<0\right)$ portfolio. The weights, similar to those in equation (1), are all positive and sum to one.

\section{Nonlinear Returns-Based Strategy}

A nonlinear weighting scheme that does not involve transaction data but puts higher weights on the more extreme winners and losers in the portfolio can be formulated as:

$$
w_{i, p, t}^{\prime}=\frac{\left(R_{i, t-1}\left(1+\left|R_{i, t-1}\right|\right)\right)}{\sum_{i=1}^{N p} R_{i, t-1}\left(1+\left|R_{i, t-1}\right|\right)}
$$

The nonlinear weights are used to examine the results of two tests: (1) the winner and loser portfolios, and (2) winners and losers with highand low-volume. In the second set, we apply only the nonlinear weights to the portfolio formed by the high- and low-volume group, though the rule does not incorporate the information from trading volume in the weighting scheme.

\section{Filter Rule Usage}

This paper modifies the overreaction portfolio formation methodologies used in past papers in order to address the economic viability of trading 
rules based upon "predictable" price movements. We boost the "signalto-noise" ratio of the security selection process used to form contrarian portfolios by using filters that screen on the magnitude of past price movements. ${ }^{4}$ The filter level places restrictions on the minimum return required for a security to be included in a long- or short-position portfolio. Thus, our study does not always invest in all securities, but only those securities whose price last period changes by at least a certain level.

This paper applies three filtering rules in each of the tests mentioned above in order to produce different subsamples with increasingly large absolute daily returns. Subsample (1), with a 0 percent filter, includes all stocks in the sample for each market. Subsamples (2) and (3) include those stocks whose absolute daily returns are greater than .5 or 1 percent respectively in each market. We find this approach appealing since the use of filters reflects what a contrarian investor would do when forming portfolios based upon the magnitude of price changes.

\section{Empirical Results}

The studies analyzing technical trading rules frequently use weekly data and often assume that the risk of the underlying portfolio remains unchanged during the holding period. Yet different weekly return behavior has been documented in high- or low-volume stocks [Conrad, Hameed, and Niden (1994) and Campbell, Grossman, and Wang (1993)]. With the assumption of constant portfolio risk over a weekly horizon becoming questionable, the use of daily data likely mitigates the problem of changes in portfolio risk. In addition, most of the published return autocorrelation analysis is based on daily data. Because daily data appear to capture the price dynamics better than weekly data, using daily data may help us evaluate whether price movements in the Pacific Basin markets follow different patterns or different response times from those of the U.S. markets.

\section{A. Returns-Based Strategy}

Table 1 reports the results of a contrarian portfolio strategy based upon historical returns in equation (2). Panel (A) reports the combined, loser,

4. Other papers that use variations of the filter-rule method include Fama and Blume (1966), Corrado and Lee (1992), and Cox and Peterson (1994). Corrado and Lee (1992) and Cox and Peterson (1994) use filter-rules in contrarian strategies using daily data. 
TABLE 1. Contrarian Profits Using Returns-Based Weights Daily Returns (x 100) Filter Rule: Zero Percent

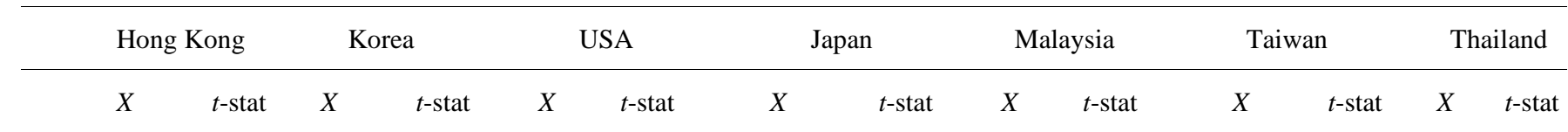

A. Returns Information Only

$\begin{array}{lrrrrrrrrrrrrrr}C & -.599 & -8.92 & -.329 & -7.7 & .967 & 11.54 & .353 & 22.29 & -.111 & -1.29 & -.76 & -14.62 & -.549 & -8.83 \\ L & .117 & 2.61 & .138 & 4.84 & .691 & 12.78 & .394 & 18.18 & .35 & 4.07 & -.213 & -4.94 & .047 & 1.09 \\ W & .716 & 10.59 & .466 & 10.38 & -.276 & -5.34 & .042 & 1.59 & .461 & 6.73 & .547 & 12.83 & .595 & 10.16\end{array}$

B. Returns-Based

\begin{tabular}{|c|c|c|c|c|c|c|c|c|c|c|c|c|c|c|}
\hline $\mathrm{CH}$ & -.63 & -9.17 & -0.266 & -6.85 & .745 & 9.29 & .429 & 23.92 & -.157 & -2.03 & -.555 & -13.22 & -.581 & -11.32 \\
\hline$C L$ & -.444 & -7.16 & -.341 & -6.63 & 1.038 & 11.71 & .391 & 24.80 & .056 & .64 & -.799 & -14.48 & -.389 & -6.95 \\
\hline$L H$ & . 187 & 3.93 & 279 & 8.99 & .729 & 10.17 & .584 & 22.70 & .527 & 5.7 & -.138 & -3.41 & .132 & 3.18 \\
\hline$L L$ & .025 & .56 & .035 & 1.17 & .543 & 13.26 & .246 & 11.87 & .168 & 2.36 & -.238 & -5.74 & .057 & 1.5 \\
\hline$W H$ & .817 & 11.01 & .546 & 11.87 & -.016 & -.41 & .155 & 5.59 & .684 & 8.93 & .417 & 10.54 & .713 & 13.6 \\
\hline$W L$ & .469 & 8.15 & .376 & 7.98 & -.495 & -7.15 & -.145 & -6.06 & .113 & 2 & .562 & 10.85 & .447 & 9.03 \\
\hline
\end{tabular}

Note: These results are from a contrarian portfolio strategy based upon historical return data shown in equation (1). Panel (A) reports the losers, winners, and combined portfolios from a returns-only strategy while panel (B) reports the losers, winners, and combined portfolios which result from a secondary grouping by high-and low-volume categories. $C$ is the combined portfolio of winners and losers, $W$ is for portfolios comprised of winnerprice stocks while $L$ reflects portfolios comprised of loser price stocks. $L L(H)$ denotes the loser portfolio with low (high) volume; $W L(H)$, the winner portfolio with low (high) volume; and $C L(H)$, the combined portfolio of losers and winners with low (high) volume. $X$ represents the mean return while the $t$-stat is the Newey-West $t$-statistic, which corrects for heteroscedasticity and auto-correlation problems. 
and winner portfolios, while panel (B) reports the combined, loser, winner portfolios that result from a secondary grouping by high- and low-volume categories.

Striking differences in the pattern of portfolio returns between the U.S. and Pacific Basin markets are found. The winner portfolios in panel A show negative returns in the U.S. market, which is an important component of contrarian trading rules. The winner portfolio returns in all other national markets are positive and, with the exception of Japan, significantly greater than the returns of the loser portfolios. Importantly, the negative autocovariance found in returns for U.S. portfolios does not appear across the other markets. The loser portfolios have consistently positive returns, with the exception of Taiwan, a finding similar to those in earlier contrarian studies. Thus, the most basic test yields evidence that these patterns of return behavior, however widely reported in U.S. markets, are not found among the Pacific Basin markets.

The contrarian trading rule produces a combined portfolio consisting of a long position in the loser portfolio and a short position in the winner portfolio, thus establishing a net-zero investment. The differences in return behavior eliminates the attractiveness of this trading rule in the Pacific Basin markets since winner portfolio returns are all positive. We find strong, positive returns for the combined portfolio only in the U.S., which is consistent with earlier studies. Additionally, the Japanese market's combined portfolio produces a small, positive return since the winner portfolio has a small positive return.

This evidence suggests that technical trading rules developed for U.S. markets may not produce the desired results in overseas markets. Importantly, we observe consistent patterns of portfolio returns across Pacific Basin markets that may be exploited by alternative trading strategies, such as those based upon momentum. Effective trading strategies should take advantage of positive autocovariance among winner stocks in these Asian markets, a situation that may offer opportunities for large profits.

Trading volume in the portfolio formation process was included to determine whether volume provides important information that may be exploited in a contrarian trading strategy. The first sort uses price data and produces the winner, loser, and combined portfolios based upon weights from equation (1), while a second sort categorizes the three portfolios into high- and low-volume groupings. panel B of table 1 reports the returns produced by a contrarian strategy using this two-way 
sort.

A second sort based upon volume produces a greater dispersion of returns among the portfolios. The winner low-volume portfolios from the U.S. and Japan are the only portfolios to have significant, negative returns, which suggests a reversal pattern in returns that could be exploited by a contrarian trading strategy. Opposite results appear in all other winner portfolios, which produce strong, positive returns.

The general pattern in returns shows that that the positive autocovariance in winner stocks from panel A becomes more pronounced in the presence of high volume. In the five PACAP markets, this pattern in returns behavior with high volume is the opposite of the predictions of Campbell, Grossman, and Wang (1993), who, in their study using U.S. stocks, suggest that higher volume would be associated with more negative autocorrelation in stock returns.

Several observations are notable in the overall results in table 1. First, we find similar returns behavior for the U.S. and Japanese markets; the other markets exhibit different return patterns. In the former two markets, returns for loser portfolios with high and low volume are positive, while winner-low volume portfolios show negative returns. Because we have positive weights invested in the loser and winner portfolios, the results imply that there are price reversals for both winner and loser portfolios. There appear to be stronger price reversals for low-volume U.S. and Japanese winner portfolios than for high-volume portfolios. With evidence of price reversals in the loser portfolios and positive autocorrelations in the winner groups, this finding differs from that in Conrad, Hameed, and Niden's (1994) examination of weekly returns of Nasdaq stocks.

Note also that the returns for loser portfolios are positive for both high- and low-volume cases, with the exception of Taiwan. These findings across markets suggest a prevailing pattern of negative autocovariance among loser stocks. The magnitude of the reversal also increases with higher trading volume, a finding that matches the results in Campbell, Grossman, and Wang (1993). The winner portfolios have positive returns for all high-volume groups (panel B), and all lowvolume groups are positive except for the U.S. and Japan. These results suggest that, for most Pacific Basin stocks, the returns of winner portfolios are positively autocorrelated while loser portfolios exhibit negative price reversals.

Test results using the .5 and 1 percent filter rules are very similar to the initial findings for the complete sample, so they are not reported. 
The price reversal and autocorrelation pattern for the large winners and losers follow the overall market behavior. The similarity of results implies that the stock returns in the overall sample may not reflect significant biases from a bid-ask bounce. The stocks meeting the requirements of the higher filters should significantly reduce the impact of possible effects of bid-ask pricing biases. We do observe that higher profits may be generated under the more restrictive filter rules. As the more restrictive filter rules (such as .5 or 1 percent) produce smaller subsamples, trading costs overall will be lower than a trading strategy using the entire sample of stocks. ${ }^{5}$

\section{B. Returns-Volume Strategy}

While our test results indicate that trading volume provides information that may be exploited in a trading strategy, volume is not the primary variable governing portfolio construction. A contrarian trading strategy that incorporates additional information from trading volume in its construction may produce significant profits. The theoretical arguments of Blume, Easley, and O'Hara (1994) and Campbell, Grossman, and Wang (1993) suggest that a significant relation may exist between current stock returns and lagged trading volume. Furthermore, if there is a trend to greater price movements in stocks trading in high volumes, the returns-volume weighting method using equation (3) ought to enable us to make greater profits using a trading strategy relying solely upon past price movements. Table 2 reports the profits of a returns transactions-based strategy that gives greater weight to high-volume stocks and less weight to low-volume securities for winner and loser portfolios. The pattern of results is similar to the earlier findings. ${ }^{6}$

The change in portfolio formation that gives greater (less) weight to stocks with high (low) trading volume also produces more positive returns for winner and loser stock portfolios. Additionally, all markets show that profits for loser and winner portfolios in the high-volume category appear to be greater than in the returns based rule (table 1).

5. We have attempted to circumvent potential mispricing biases by conducting tests using larger filter rules and different holding periods. Larger filter levels reduce the relative impact of potential bid-ask since the .5 or 1 percent return that is required to be included in the portfolio sample would represent much if not all of any potential bid-ask pricing error.

6. Note that Conrad, Hameed, and Niden (1994) find high (low) volume to be associated with negative (positive) autocovariance in weekly stock returns. This pattern does not appear with the daily data in our study. 
TABLE 2. Contrarian Profits Using Returns/Volume Weights Daily Returns (x 100) Filter Rule: Zero Percent

\begin{tabular}{|c|c|c|c|c|c|c|c|c|c|c|c|c|c|c|}
\hline & \multicolumn{2}{|c|}{ Hong Kong } & \multicolumn{2}{|c|}{ Korea } & \multicolumn{2}{|c|}{ USA } & \multicolumn{2}{|c|}{ Japan } & \multicolumn{2}{|c|}{ Malaysia } & \multicolumn{2}{|c|}{ Taiwan } & \multicolumn{2}{|c|}{ Thailand } \\
\hline & $X$ & $t$-stat & $X$ & $t$-stat & $X$ & $t$-stat & $X$ & $t$-stat & $X$ & $t$-stat & $X$ & $t$-stat & $X$ & $t$-stat \\
\hline $\mathrm{CH}$ & -.76 & -8.87 & -.34 & -7.57 & .92 & 7.3 & .35 & 13.55 & -.21 & -2.74 & -.72 & -14.76 & -.52 & -9.9 \\
\hline$C L$ & -.45 & -7.7 & -.36 & -7.88 & .72 & 15.51 & .43 & 26.83 & .03 & .37 & -.65 & -13.31 & -.48 & -8.91 \\
\hline$L H$ & .23 & 4.26 & .26 & 7.71 & .98 & 8.67 & .65 & 22.96 & .57 & 5.75 & -.21 & -4.75 & .17 & 3.71 \\
\hline$L L$ & .03 & .65 & .05 & 1.78 & .49 & 14.23 & .3 & 13.99 & .19 & 2.57 & -.17 & -4.21 & .03 & .93 \\
\hline$W H$ & .98 & 10.98 & .6 & 12.2 & .06 & .9 & .3 & 9.07 & .78 & 9.17 & .51 & 12.13 & .69 & 12.85 \\
\hline$W L$ & .48 & 8.33 & .41 & 9.17 & -.23 & -6.03 & -.13 & -5.11 & .16 & 2.82 & .48 & 9.89 & .51 & 10.68 \\
\hline
\end{tabular}

Note: These reported profits are from a returns-transactions based strategy that gives greater weight to high-volume stocks and less weight to lowvolume securities for winner and loser portfolios. $L L(H)$ denotes the loser portfolio with low (high) volume; $W L(H)$, the winner portfolio with low (high) volume; and $C L(H)$, the combined portfolio of losers and winners with low (high) volume. $X$ represents the mean return while the $t$-stat is the NeweyWest t-statistic, which corrects for heteroscedasticity and autocorrelation problems. 
Greater profits are not generated among the low-volume stocks. These results support the idea that trading volume provides additional information by which to produce higher trading profits, although the pattern for Pacific stocks does not appear to coincide with that suggested by Campbell, Grossman, and Wang (1993). ${ }^{7}$

The findings reveal that the inclusion of trading volume in a contrarian trading strategy does not appear to provide support for price reversals in the Pacific Basin markets. If abnormal trading volume provided additional information on increased return reversal, then the cross-product of current returns and lagged high (low) trading volume should be negative (positive) for winner stocks and positive (negative) for loser stocks. We find a complete reversal in signs, which suggests positive autocovariance in returns, not reversals.

This article finds minimal impact of the contemporaneous relation between lagged volume and lagged returns upon contrarian profits. The cross-products $\left(R_{t-1} V_{t-1}\right)$ are smaller magnitudes than the results of the cross-product of lagged changes, implying that contrarian profits would not be based upon the interaction of the prior period's return and trading volume. $^{8}$

\section{Nonlinear Returns-Based Weights}

The reversal pattern of winner and loser stocks may be enhanced by emphasizing stocks with larger price changes, and the nonlinear weighting method using equation (4) focuses upon such securities. Table 3 presents the portfolio returns produced by the nonlinear returnsbased method. In panel A, the results show that the U.S. securities produce much higher contrarian profits than when a linear weighting scheme is used to form portfolios (table 1). Stocks in the other markets display a pattern of return reversals where loser (winner) stocks exhibit negative (positive) autocovariances.

While the weighting methods produce significantly different returns for the U.S. stocks, the returns for Pacific Basin securities in table 3 are only slightly higher than those shown in table 1, panel A. Thus, there results.

7. Although not reported, test results using .5 and 1 percent filter rules provide similar

8. The result of cross-product changes in (1) lagged volume and current returns and (2) lagged volume and lagged returns are not reported, but are available from the authors upon request. Results of tests using the .5 and 1 percent filter rules are similar, so we do not formally present these results. 
TABLE 3. Contrarian Profits Using Nonlinear Returns-Based Weights Daily Returns (x 100) Filter Rule: Zero Percent

\begin{tabular}{|c|c|c|c|c|c|c|c|c|c|c|c|c|c|c|}
\hline & \multicolumn{2}{|c|}{ Hong Kong } & \multicolumn{2}{|c|}{ Korea } & \multicolumn{2}{|c|}{ USA } & \multicolumn{2}{|c|}{ Japan } & \multicolumn{2}{|c|}{ Malaysia } & \multicolumn{2}{|c|}{ Taiwan } & \multicolumn{2}{|c|}{ Thailand } \\
\hline & $X$ & $t$-stat & $X$ & $t$-stat & $X$ & $t$-stat & $X$ & $t$-stat & $X$ & $t$-stat & $X$ & $t$-stat & $X$ & $t$-stat \\
\hline \multicolumn{15}{|c|}{ A. Returns Information Only } \\
\hline$C$ & -.62 & -8.78 & -.33 & -7.5 & 1.25 & 9.94 & .36 & 22.07 & -.08 & -.85 & -.77 & -14.73 & -.56 & -8.85 \\
\hline$L$ & .12 & 2.65 & .14 & 4.87 & .8 & 11.7 & .41 & 18.53 & .39 & 4.13 & -.22 & -5.04 & .05 & 1.1 \\
\hline$W$ & .74 & 10.52 & .48 & 10.28 & -.45 & -5.5 & .05 & 1.69 & .47 & 6.65 & .56 & 12.95 & .6 & 10.19 \\
\hline
\end{tabular}

B. Nonlinear Returns-Based Weights for High- and Low-Volume Stocks

\begin{tabular}{|c|c|c|c|c|c|c|c|c|c|c|c|c|c|c|}
\hline $\mathrm{CH}$ & -.65 & -9 & -.27 & -6.75 & .88 & 8.5 & .44 & 23.48 & -.13 & -1.60 & -.56 & -13.33 & -.59 & -11.37 \\
\hline$C L$ & -.45 & -7.09 & -.34 & -6.5 & 1.26 & 9.85 & .40 & 24.71 & .08 & 0.89 & -.81 & -14.63 & -.39 & -6.97 \\
\hline$L H$ & .19 & 3.97 & .28 & 8.97 & .84 & 9.09 & .60 & 22.95 & .56 & 5.66 & -.14 & -3.49 & .13 & 3.18 \\
\hline$L L$ & .03 & .61 & .04 & 1.27 & .6 & 12.67 & .25 & 12.18 & .2 & 2.53 & -.24 & -5.82 & .06 & 1.57 \\
\hline$W H$ & .84 & 10.86 & .56 & 11.74 & -.05 & -.98 & .16 & 5.62 & .69 & 8.89 & .42 & 10.62 & .72 & 13.68 \\
\hline$W L$ & .48 & 8.2 & .38 & 7.94 & -.66 & -6.23 & -.15 & -5.99 & .11 & 1.97 & .57 & 10.94 & .45 & 9.07 \\
\hline
\end{tabular}

Note: Reported returns reflect the use of a nonlinear weighting method shown in equation (4) that exploits any reversal patterns in securities. This method of portfolio construction places greater weight on the previous period's extreme winners and losers. $C$ is the combined portfolio of winners and losers, $W$ is for portfolios comprised of winner-price stocks while $L$ reflects portfolios comprised of loser price stocks. $L L(H)$ denotes the loser portfolio with low (high) volume; $W L(H)$, the winner portfolio with low (high) volume; and $C L(H)$, the combined portfolio of losers and winners with low (high) volume. $X$ represents the mean return while the $t$-stat is the Newey-West $t$-statistic, which corrects for heteroscedasticity and autocorrelation problems 
is a disparity in the information content for extreme winners and losers in U.S. and Pacific securities.

Panel B presents the portfolio returns after initially grouping securities on the basis of high or low trading volume, and then applying the nonlinear returns-based portfolio weights. The returns from this strategy are generally greater than those in table 1, panel B, by the same degree of magnitude as observed in panel A. The table 3 returns are smaller than those in table 2, which suggests that portfolios formed according to a nonlinear weighting of trading volume outperform similar schemes based upon past returns. This pattern holds across all levels of trading volume.

The differences between table 3 and table 2 suggest that the extremes of previous trading volume convey more information than the prior period's winners and losers. Thus, the contrarian strategy does not appear to work in non-U.S. markets, although other trading strategies should be able to exploit the strong pattern of positive autocovariance that is seen in the Pacific Basin stocks. ${ }^{9}$

\section{Alternative Volume Measures}

Information embodied in trading volume during portfolio construction appears to produce greater portfolio returns. While our first tests use the previous day's trading volume, additional information may be contained in trades over a longer horizon. Thus, we analyze the portfolio returns formed by winner and loser stocks sorted by the number of trades over the previous 5 and 22 days.

The portfolio results based on the 5-day and 22-day volume metrics are quite similar to the previous results, so they are not formally reported here. The winner stocks with high volume $(W H)$ yield slightly higher returns than those of earlier tests that use linear weighting schemes for trading volume while these returns are usually greater with nonlinear volume weights (table 2).

The similarity in returns suggests that no additional information is contained within trading volume from earlier time periods except for winner stocks with a longer period of high trading activity. Thus, we continue to observe a pattern across markets of a positive autocovariance among winner stocks. The results also indicate that

9. The .5 and 1 percent filter rules provide similar results, although with slightly higher profits than do those for the entire sample. 
different markets have different price/volume behaviors that reflect their unique market characteristics. ${ }^{10}$

\section{E. The Return Transaction Rule on Size-Ranked Portfolios}

Studies have linked firm size with differences in returns behavior, a matter of importance to contrarian trading strategies. For example, Blume, Easley, and O'Hara (1994) propose that trading volume may contain more information for smaller firms, which would impact price movement. Empirical studies such as Conrad, Hameed, and Niden (1994) also show that portfolios of smaller U.S. securities yield greater profits than those of larger firms when partitioned on trading information.

We group firms in each market into five size-based portfolios (Group 1 portfolios represent the smallest securities) and find different return patterns between the U.S. and Pacific markets. We use the original weighting scheme from equation (3) to form portfolios within the size quintiles, and present the average trading profits for the portfolios of each country in table 4. For Pacific Basin stocks, winner stock returns display evidence of positive autocovariance, while loser stocks exhibit reversals. The winner portfolios of U.S. stock returns display the reversal behavior only in the smaller quintiles, but evidence of positive autocovariance emerges in the largest quintiles.

Opposite return patterns in the winner portfolios of U.S. and Pacific Basin stocks are found; the Pacific stock returns diminish monotonically as size increases. The winner high-volume portfolios of the latter exhibit a steeper decline than do the winner-low-volume portfolios. Interestingly, the U.S. portfolios of winner stocks display the opposite trend; the smallest portfolios have the greatest reversal, hence the most negative returns. The portfolios of the larger U.S. stocks exhibit positive autocovariance. These findings contrast with those of Conrad, Hameed, and Niden (1994) who work with weekly returns. The pattern and amount of returns for size-based portfolios do not vary significantly when we apply the .5 and 1 percent filter rules, so the results presented in table 4 should not be affected by a bid-ask bounce.

There is an inverse relation between size and portfolio returns for the loser portfolios in the U.S., Japanese, and Malaysian markets. This pattern holds for both the high- and low-volume portfolios in these

10. Additionally, results using different filtering rules with .5 and 1 percent yield similar results, and thus they are robust. 
TABLE 4. Contrarian Profits Using Returns/Volume Weights Size-Ranked Portfolios Daily Returns (x 100) Filter Rule: Zero Percent



A. Contrarian Strategy with Quintile 1 (Smallest) Portfolios

$\begin{array}{lrrrrrrrrrrrrrr}C H & -1.21 & -14.34 & -.39 & -3.71 & 3.46 & 11.43 & .32 & 6.11 & -.72 & -7.98 & -.69 & -12.38 & -.4 & -9.09 \\ C L & -.79 & -11.53 & -.5 & -4.16 & 3.47 & 17.86 & .48 & 13.57 & -.2 & -2.18 & -.82 & -12.5 & -.04 & -.84 \\ L H & .34 & 7.64 & .08 & .9 & 2.74 & 10.92 & .93 & 22.55 & .49 & 5.91 & -.22 & -4.63 & .52 & 20.60 \\ L L & .01 & .25 & -.11 & -1.54 & 2.07 & 16.80 & .43 & 13.42 & .11 & 1.73 & -.27 & -6.43 & .21 & 7.67 \\ W H & 1.55 & 17.22 & .46 & 4.13 & -0.71 & -4.86 & .61 & 11.94 & 1.22 & 12.31 & .46 & 9.38 & .91 & 21.54 \\ W L & .8 & 14.04 & .39 & 3.5 & -1.41 & -10.39 & -.05 & -1.39 & .31 & 4.33 & .55 & 9.55 & .25 & 6.56\end{array}$

B. Contrarian Strategy with Quintile 5 (Largest) Portfolios

$\begin{array}{lcccccccccccccc}C H & -.27 & -6.21 & -.06 & -1.05 & -.21 & -9.4 & .27 & 9.98 & -.18 & -4.82 & -.12 & -4.17 & -.18 & -5.34 \\ C L & -.19 & -5.08 & -.15 & -2.42 & -.12 & -8.09 & .32 & 16.7 & -.02 & -.5 & -.14 & -4.82 & -.21 & -6.45 \\ L H & .18 & 4.78 & .05 & .94 & -.03 & -1.13 & .32 & 14.3 & .27 & 5.97 & .1 & 3.65 & .14 & 4.8 \\ L L & .03 & .9 & -.4 & -.94 & .01 & .7 & .18 & 9.1 & .07 & 1.66 & .03 & 1.31 & .09 & 3.17 \\ W H & .45 & 9.4 & .1 & 1.7 & .19 & 7.41 & .05 & 1.73 & .45 & 9.76 & .22 & 6.46 & .32 & 8.94 \\ W L & .22 & 4.98 & .11 & 1.52 & .14 & 6.99 & -.14 & -5.54 & .09 & 2.47 & .17 & 5.02 & .29 & 9.25\end{array}$

Note: These returns occur from the original weighting scheme from equation (3) that forms portfolios within size quintiles. $L L(H)$ denotes the loser portfolio with low (high) volume; $W L(H)$, the winner portfolio with low (high) volume; $C L(H)$, the combined portfolio of losers and winners with low (high) volume. $X$ represents the mean return while the $t$-stat is the Newey-West $t$-statistic, which corrects for heteroscedasticity 
markets. The negative autocovariance of the loser portfolios diminishes as firm size increases within these markets, thus, a return-size trend does not appear among the loser portfolios of the other markets.

\section{F. Change in Risk and Trading}

The portfolio data for changes in risk after the implementation of the technical rules is analyzed. While Lehmann (1990) argues that a week is too short to observe significant changes in expected returns, studies such as Conrad, Kaul, and Nimalendran (1991) and Conrad, Hameed, and Niden (1994) have produced evidence that weekly returns may be affected by changes in risk level. We argue that it is not unreasonable to suggest that, on average, daily returns would not show significant changes in risk. Thus, we can make a strong argument for the use of daily data in a study of contrarian profits.

The variances of portfolios are calculated on the day of evaluation and five days earlier to assess the magnitude of changes in risk levels. ${ }^{11}$ The sample variances of the portfolios change very little, if at all, during the elapsed time, and we find no consistent pattern across markets. The only marginal increase in volatility is for high-volume U.S. portfolios. The low-volume portfolios experience either a small decrease or no change in volatility during the five-day period.

Although these patterns may be consistent across markets, it also remains unlikely that significant changes in expected returns would occur over this short time frame. The absence of strong contrarian profits from portfolios formed daily may be partially explained by the negligible changes in risk level within these portfolios.

\section{G. Longer Holding Periods, the Bid-Ask Bounce, and Transaction Costs}

One intrinsic difficulty in applying a technical trading rule to daily data is that trading profits may be overstated by a bid-ask bounce [Ball, Kothari, and Wasley (1995)]. Conrad, Gultekin and Kaul (1997) examine short-run contrarian strategies and assess the importance of bid-ask bias and risk. They observe that profits reported in such studies as Lehmann (1990) and Lo and MacKinlay (1990) are eliminated when the analysis includes risk and transaction costs. Yet these initial studies produced significant advancements in the understanding of return

11. The results of this analysis are not reported but are available from the authors on request. 
behavior even in the absence of reported economic profits.

To circumvent any potential mispricing bias, tests using longer holding periods as well as larger filter rules are conducted. ${ }^{12}$ The combined effects of these strategies would reduce the frequency of transactions and the exposure to any bias from a bid-ask bounce. While some studies of U.S. stocks have tried to eliminate this mispricing effect by using the midpoint between the bid and ask prices, such price data are not widely available in these Pacific markets. If a bid-ask bounce were to be the source of trading profits instead of the assumed price reversal/continuation phenomenon, we would expect to find similar patterns of trading profits across national stock markets. More important, the trading profits derived under the same technical rule would disappear over longer holding-period horizons, because the effect of the bid-ask bounce on the trading profits would diminish over time.

The longer-horizon performance of portfolios formed by the returns/volume methodology is analyzed to determine if there are changes in return patterns from the earlier tests using one-day holding periods. Table 5 reports the results for all portfolios for both high and low transactions groups with holding period returns of one-day (panel A), four-days (panel B) and one-week (panel C). ${ }^{13}$ We find patterns of return behaviors similar to those reported earlier. Importantly, we find that the returns do not change signs over longer horizons, a finding that is consistent across national markets. Results from the U.S. markets also conform to earlier studies, thus there is no detectable evidence of a bias that may originate from a bid-ask mispricing. Additionally, the reported returns either remain stable or increase slightly as the time horizon lengthens. The consistency of these patterns across markets and across holding period horizons provides strong evidence that these profits are the results of actual price movements and are not induced by data irregularities from bid-ask mispricing.

Transaction costs have two components, brokerage fees and market impact costs. Hence, determining the precise level of transaction costs for buying and selling assets can be difficult. ${ }^{14}$ See, for instance,

12. In an earlier section, we address the negating effect that larger filter levels would have upon the relative impact of potential bid-ask bounces.

13. Results from applying .5 and 1 percent filter rules are similar to tests using the entire sample of firms. We include the results from the one-day return for comparative purposes.

14. Besides transaction costs, it is possible that taxes may differ between active and passive trading strategies and across markets. Our results do not directly account for taxes. 
TABLE 5. Holding Period Returns to Contrarian Portfolio Strategy Returns/Volume Weights Daily Returns (x 100) Filter Rule: Zero Percent

\begin{tabular}{|c|c|c|c|c|c|c|c|c|c|c|c|c|c|c|}
\hline & \multicolumn{2}{|c|}{ Hong Kong } & \multicolumn{2}{|c|}{ Korea } & \multicolumn{2}{|c|}{ USA } & \multicolumn{2}{|c|}{ Japan } & \multicolumn{2}{|c|}{ Malaysia } & \multicolumn{2}{|c|}{ Taiwan } & \multicolumn{2}{|c|}{ Thailand } \\
\hline & $X$ & $t$-stat & $X$ & $t$-stat & $X$ & $t$-stat & $X$ & $t$-stat & $X$ & $t$-stat & $X$ & $t$-stat & $X$ & $t$-stat \\
\hline \multicolumn{15}{|c|}{ A. Portfolios Returns in Day $t$} \\
\hline $\mathrm{CH}$ & -.757 & -8.87 & -.342 & -7.57 & .924 & 7.3 & .349 & 13.55 & -.33 & -4.73 & -.719 & -14.76 & -.523 & -9.9 \\
\hline$C L$ & -.448 & -7.7 & -.359 & -7.88 & .719 & 15.51 & .427 & 26.83 & .033 & .38 & -.647 & -13.31 & -.477 & -8.91 \\
\hline$L H$ & .225 & 4.26 & .259 & 7.71 & .981 & 8.67 & .651 & 22.96 & .519 & 6 & -.214 & -4.75 & .168 & 3.71 \\
\hline$L L$ & .028 & .65 & .052 & 1.78 & .489 & 14.23 & .302 & 13.99 & .194 & 2.57 & -.169 & -4.21 & .034 & .93 \\
\hline$W H$ & .983 & 10.98 & .602 & 12.20 & .057 & .9 & .302 & 9.07 & .849 & 9.39 & .505 & 12.13 & .69 & 12.85 \\
\hline$W L$ & .476 & 8.33 & .411 & 9.17 & -.23 & -6.03 & -.125 & -5.11 & .161 & 2.82 & .479 & 9.89 & .511 & 10.68 \\
\hline \multicolumn{15}{|c|}{ B. Portfolio Returns in Day $t+4$} \\
\hline $\mathrm{CH}$ & -.544 & -7.13 & -0.143 & -1.70 & 2.457 & 3.02 & .672 & 13.61 & -.309 & -3.82 & -1.435 & -12.08 & -.661 & -6.65 \\
\hline$C L$ & -.325 & -4.83 & -0.265 & -3.57 & 1.151 & 19.83 & .643 & 22.82 & .056 & .61 & -1.304 & -10.64 & -1.003 & -10.62 \\
\hline$L H$ & .499 & 3.9 & 0.995 & 8.68 & 2.514 & 3.08 & 1.137 & 12.32 & .84 & 5.44 & -.047 & -.24 & .902 & 6.38 \\
\hline$L L$ & .399 & 2.99 & 0.654 & 5.54 & .95 & 8.22 & .666 & 7.48 & .571 & 3.59 & .065 & .36 & .696 & 5.04 \\
\hline$W H$ & 1.025 & 7.34 & 1.142 & 7.91 & .057 & .43 & .466 & 4.84 & 1.15 & 7.15 & 1.387 & 7.51 & 1.656 & 10.65 \\
\hline$W L$ & .7 & 5.44 & 0.923 & 6.83 & -.201 & -1.79 & .023 & .26 & .528 & 3.92 & 1.359 & 6.95 & 1.729 & 11.41 \\
\hline
\end{tabular}


TABLE 5. (Continued)

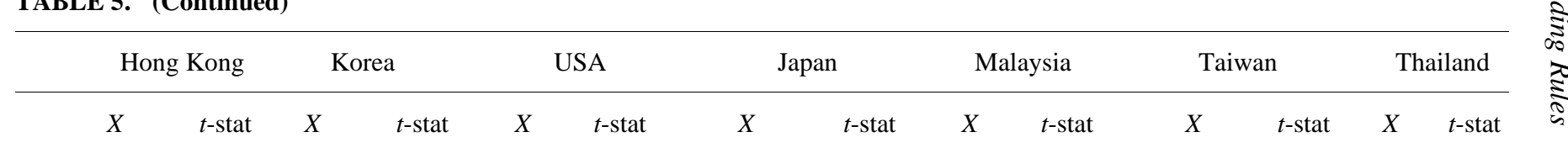

C. Portfolio Returns in Day $t+5$

\begin{tabular}{|c|c|c|c|c|c|c|c|c|c|c|c|c|c|c|}
\hline $\mathrm{CH}$ & -.568 & -8.87 & -.166 & -7.57 & 1.734 & 7.3 & .682 & 13.55 & -.33 & -4.73 & -1.477 & -14.76 & -.581 & -9.9 \\
\hline$C L$ & -.337 & -7.7 & -.241 & -7.88 & 1.21 & 15.51 & .64 & 26.83 & .019 & .38 & -1.349 & -13.31 & -1.075 & -8.91 \\
\hline$L H$ & .552 & 4.26 & 1.088 & 7.71 & 1.828 & 8.67 & 1.205 & 22.96 & .913 & 6 & .034 & -4.75 & 1.146 & 3.71 \\
\hline$L L$ & .467 & .65 & .782 & 1.78 & 1.032 & 14.23 & .715 & 13.99 & .655 & 2.57 & .155 & -4.21 & .858 & .93 \\
\hline$W H$ & 1.101 & 10.98 & 1.258 & 12.2 & .094 & .9 & .523 & 9.07 & 1.249 & 9.39 & 1.51 & 12.13 & 1.84 & 12.85 \\
\hline$W L$ & .767 & 8.33 & 1.026 & 9.17 & -.178 & -6.03 & .074 & -5.11 & .642 & 2.82 & 1.502 & 9.89 & 1.955 & 10.68 \\
\hline
\end{tabular}

Note: The portfolio returns reflect longer horizon performances of portfolios formed by the returns/volume methodology using both high-and low-transactions groups for specific days after portfolio formation. $L L(H)$ denotes the loser portfolio with low (high) volume; $W L(H)$, the winner portfolio with low (high) volume; and $C L(H)$, the combined portfolio of losers and winners with low (high) volume. $X$ represents the mean return while the $t$-stat is the Newey-West $t$-statistic, which corrects for heteroscedasticity and autocorrelation problems. 
Berkowitz, Logue, and Noser (1988) and Chan and Lakonishok (1995, 1997). In our analysis, we employ various filters to capture the gamut of potential transaction costs. In particular, we apply larger filtering restrictions across the different holding periods to determine if the behavior of returns changes. The results are similar to those presented in table 6 and are not reported. The results across holding periods, after using the .5- and 1-percent filtering rules, provides further evidence that our results are not driven by a bid-ask bounce. Stock returns in Pacific Basin markets consistently exhibit behavior that differs from the U.S. market.

This article demonstrates that different return patterns in the Pacific Basin would not accommodate a contrarian trading strategy that is successful in the U.S., but we also introduce transaction costs to determine the economic viability to daily trading. Table 6 shows the impact that a .5-percent transaction cost has upon the daily trading strategy. We find that most profits disappear with a transaction cost a .5-percent while a 1-percent transaction cost eliminates almost all profits reported earlier. ${ }^{15}$ Thus, reducing the frequency of trades lessens the effect of transaction costs and also diminishes the impact of any biases that may occur from a bid-ask bounce.

\section{H. Yearly Performance}

Our primary results show that Pacific Basin stock markets for our sample period exhibit negative autocorrelation for losing portfolios and positive autocorrelation for winning portfolios. These results reflect average performances, and a potential interpretation would be that investors should buy all stocks because, no matter what happens, losers will pay off while winners will continue to outperform the market. We conduct a yearly analysis of return behavior to determine if variations occur throughout the sample period, a time when Asian economies experienced significant growth. Table 7 displays the year-by-year results of winner and loser portfolios for all markets in our sample. We include the respective value-weighted market indices for comparative purposes, though the combined portfolios are omitted to conserve space. These results demonstrate that the strong upward trend of the markets is an important factor contributing to the misperception that no losses occur in these markets.

15. The authors do not present the results of the 1-percent transaction cost, but results will be provided upon request. 
TABLE 6. Transaction Costs and Holding-Period Returns A Contrarian Portfolio Strategy Average Daily Returns (x 100) 1980-1993 Filter Rule: Zero Percent

\begin{tabular}{|c|c|c|c|c|c|c|c|c|c|c|c|c|c|c|}
\hline & \multicolumn{2}{|c|}{ Hong Kong } & \multicolumn{2}{|c|}{ Korea } & \multicolumn{2}{|c|}{ USA } & \multicolumn{2}{|c|}{ Japan } & \multicolumn{2}{|c|}{ Malaysia } & \multicolumn{2}{|c|}{ Taiwan } & \multicolumn{2}{|c|}{ Thailand } \\
\hline & $X$ & $t$-stat & $X$ & $t$-stat & $X$ & $t$-stat & $X$ & $t$-stat & $X$ & $t$-stat & $X$ & $t$-stat & $X$ & $t$-stat \\
\hline$C$ & -1.6 & $(-23.81)$ & -1.33 & $(-31.14)$ & -.03 & $(-.4)$ & -.65 & $(-40.9)$ & -1.11 & $(-12.83)$ & -1.76 & $(-33.85)$ & -1.55 & $(-24.93)$ \\
\hline$L$ & -.38 & $(-8.53)$ & -.36 & $(-12.71)$ & .19 & (3.53) & -.11 & $(-4.86)$ & -.15 & $(-1.75)$ & -.71 & $(-16.54)$ & -.45 & $(-1.56)$ \\
\hline$W$ & .22 & $(3.2)$ & -.03 & $(-.75)$ & -.78 & $(-15)$ & -.46 & $(-17.53)$ & -.04 & $(-.57)$ & .05 & (1.1) & .1 & $(1.62)$ \\
\hline
\end{tabular}

Note: The average daily returns are from a contrarian portfolio strategy based upon historical return data shown in equation (1). $C$ is the combined portfolio of winners and losers, $L$ is portfolios of loser stocks while $W$ is portfolios of winner stocks. A simulated transaction cost of .5 percent is incorporated in the return calculation. $X$ is the mean return, and the $t$-stat is the Newey-West $t$-statistic, which corrects for heteroscedasticity and autocorrelation problems. 
TABLE 7. Holding-Period Returns for a Contrarian Portfolio Strategy Yearly Performance with Daily Returns (x 100)Filter Rule: Zero Percent

\begin{tabular}{cccccccccccccccc}
\hline 1980 & 1981 & 1982 & 1983 & 1984 & 1985 & 1986 & 1987 & 1988 & 1989 & 1990 & 1991 & 1992 & 1993 & $80-93$ \\
\hline$X$ & $X$ & $X$ & $X$ & $X$ & $X$ & $X$ & $X$ & $X$ & $X$ & $X$ & $X$ & $X$ & $X$ & $X$ \\
\hline
\end{tabular}

\begin{tabular}{|c|c|c|c|c|c|c|c|c|c|c|c|c|c|c|c|}
\hline \multicolumn{16}{|l|}{ Hong Kong } \\
\hline$L$ & $\begin{array}{c}.31 \\
(1.93)\end{array}$ & $\begin{array}{c}.28 \\
(1.82)\end{array}$ & $\begin{array}{c}.19 \\
(1.13)\end{array}$ & $\begin{array}{c}.32 \\
(1.33)\end{array}$ & $\begin{array}{c}.37 \\
(2.11)\end{array}$ & $\begin{array}{c}-.01 \\
(-.07)\end{array}$ & $\begin{array}{c}.01 \\
(.06)\end{array}$ & $\begin{array}{c}-.02 \\
(-.07)\end{array}$ & $\begin{array}{c}.09 \\
(.76)\end{array}$ & $\begin{array}{c}-.06 \\
(-.26)\end{array}$ & $\begin{array}{l}.02 \\
(.1)\end{array}$ & $\begin{array}{c}.07 \\
(0.88)\end{array}$ & $\begin{array}{c}-.05 \\
(-.55)\end{array}$ & $\begin{array}{c}.13 \\
(1.31)\end{array}$ & $\begin{array}{r}.117 \\
(2.61)\end{array}$ \\
\hline$W$ & $\begin{array}{c}1.04 \\
(4.07)\end{array}$ & $\begin{array}{c}.61 \\
(2.63)\end{array}$ & $\begin{array}{l}-.09 \\
(-.38)\end{array}$ & $\begin{array}{c}.43 \\
(1.69)\end{array}$ & $\begin{array}{c}.42 \\
(1.58)\end{array}$ & $\begin{array}{c}.62 \\
(4.91)\end{array}$ & $\begin{array}{c}1.27 \\
(4.43)\end{array}$ & $\begin{array}{c}1.68 \\
(6.09)\end{array}$ & $\begin{array}{c}.75 \\
(4.54)\end{array}$ & $\begin{array}{c}.78 \\
(3.23)\end{array}$ & $\begin{array}{c}.67 \\
(2.94)\end{array}$ & $\begin{array}{c}.32 \\
(3.03)\end{array}$ & $\begin{array}{c}.71 \\
(4.46)\end{array}$ & $\begin{array}{c}.81 \\
(6.19)\end{array}$ & $\begin{array}{c}.72 \\
(10.59)\end{array}$ \\
\hline $\begin{array}{l}\text { Market } \\
\text { Korea }\end{array}$ & .21 & .01 & -.22 & .07 & .14 & .16 & .17 & -.02 & .09 & .05 & .03 & .14 & .1 & .3 & .09 \\
\hline$L$ & $\begin{array}{c}.18 \\
(1.84)\end{array}$ & $\begin{array}{c}.28 \\
(1.79)\end{array}$ & $\begin{array}{c}.31 \\
(2.39)\end{array}$ & $\begin{array}{c}.17 \\
(2.45)\end{array}$ & $\begin{array}{c}.27 \\
(4.26)\end{array}$ & $\begin{array}{c}.44 \\
(5.11)\end{array}$ & $\begin{array}{c}.2 \\
(2.29)\end{array}$ & $\begin{array}{c}.01 \\
(.07)\end{array}$ & $\begin{array}{r}.16 \\
(2.1)\end{array}$ & $\begin{array}{c}.02 \\
(.35)\end{array}$ & $\begin{array}{c}-.02 \\
(-.24)\end{array}$ & $\begin{array}{c}.04 \\
(.41)\end{array}$ & $\begin{array}{l}-.05 \\
(-.41)\end{array}$ & $\begin{array}{c}-.08 \\
(-.74)\end{array}$ & $\begin{array}{c}.14 \\
(4.84)\end{array}$ \\
\hline$W$ & $\begin{array}{c}.34 \\
(1.94)\end{array}$ & $\begin{array}{c}.58 \\
(2.96)\end{array}$ & $\begin{array}{c}.63 \\
(4.77)\end{array}$ & $\begin{array}{c}.29 \\
(1.98)\end{array}$ & $\begin{array}{c}.43 \\
(2.84)\end{array}$ & $\begin{array}{c}.55 \\
(3.42)\end{array}$ & $\begin{array}{c}.89 \\
(6.16)\end{array}$ & $\begin{array}{c}1.02 \\
(5.73)\end{array}$ & $\begin{array}{r}.54 \\
(4.2)\end{array}$ & $\begin{array}{c}.22 \\
(2.19)\end{array}$ & $\begin{array}{c}.06 \\
(.48)\end{array}$ & $\begin{array}{l}-.06 \\
(-.51)\end{array}$ & $\begin{array}{c}.6 \\
(3.95)\end{array}$ & $\begin{array}{c}.44 \\
(3.28)\end{array}$ & $\begin{array}{c}.47 \\
(10.38)\end{array}$ \\
\hline $\begin{array}{l}\text { Market } \\
\text { USA }\end{array}$ & .05 & .19 & .07 & .04 & .12 & .11 & .22 & .23 & .18 & -.02 & -.08 & -.03 & .05 & .09 & .09 \\
\hline$L$ & $\begin{array}{c}.4 \\
(3.84)\end{array}$ & $\begin{array}{r}.19 \\
(2.6)\end{array}$ & $\begin{array}{c}.36 \\
(3.48)\end{array}$ & $\begin{array}{c}.21 \\
(3.12)\end{array}$ & $\begin{array}{c}.17 \\
(2.44)\end{array}$ & $\begin{array}{r}.55 \\
(5.9)\end{array}$ & $\begin{array}{c}.47 \\
(5.63)\end{array}$ & $\begin{array}{c}.47 \\
(3.98)\end{array}$ & $\begin{array}{c}.72 \\
(9.76)\end{array}$ & $\begin{array}{c}.94 \\
(9.64)\end{array}$ & $\begin{array}{l}1.2 \\
(6.25)\end{array}$ & $\begin{array}{c}1.87 \\
(6.48)\end{array}$ & $\begin{array}{c}1.37 \\
(4.92)\end{array}$ & $\begin{array}{c}.77 \\
(13.31)\end{array}$ & $\begin{array}{c}.69 \\
(12.78)\end{array}$ \\
\hline$W$ & $\begin{array}{l}.1 \\
(.87)\end{array}$ & $\begin{array}{c}.02 \\
(.21)\end{array}$ & $\begin{array}{l}.11 \\
(.9)\end{array}$ & $\begin{array}{c}.29 \\
(3.54)\end{array}$ & $\begin{array}{l}-.06 \\
(-.97)\end{array}$ & $\begin{array}{c}-.02 \\
(-.22)\end{array}$ & $\begin{array}{c}-.11 \\
(-1.33)\end{array}$ & $\begin{array}{l}-.17 \\
(-.87)\end{array}$ & $\begin{array}{c}-.45 \\
(-4.21)\end{array}$ & $\begin{array}{c}-.64 \\
(-6.24)\end{array}$ & $\begin{array}{c}-.72 \\
(-3.39)\end{array}$ & $\begin{array}{l}-1.15 \\
(-3.95)\end{array}$ & $\begin{array}{c}-.65 \\
(-2.58)\end{array}$ & $\begin{array}{c}-.41 \\
(-3.47)\end{array}$ & $\begin{array}{c}-.28 \\
(-5.34)\end{array}$ \\
\hline Market & .11 & -.02 & .07 & .08 & .01 & .11 & .06 & .01 & .06 & .1 & -.02 & .11 & .03 & .04 & .05 \\
\hline
\end{tabular}


TABLE 7. (Continued)

\begin{tabular}{|c|c|c|c|c|c|c|c|c|c|c|c|c|c|c|c|}
\hline & 1980 & 1981 & 1982 & 1983 & 1984 & 1985 & 1986 & 1987 & 1988 & 1989 & 1990 & 1991 & 1992 & 1993 & $80-93$ \\
\hline & $X$ & $X$ & $X$ & $X$ & $X$ & $X$ & $X$ & $X$ & $X$ & $X$ & $X$ & $X$ & $X$ & $X$ & $X$ \\
\hline \multicolumn{16}{|l|}{ Japan } \\
\hline$L$ & $\begin{array}{c}.37 \\
(10.21)\end{array}$ & $\begin{array}{c}.27 \\
(6.91)\end{array}$ & $\begin{array}{r}.44 \\
(11.3)\end{array}$ & $\begin{array}{c}.53 \\
(19.94)\end{array}$ & $\begin{array}{c}.47 \\
(12.82)\end{array}$ & $\begin{array}{c}.44 \\
(16.54)\end{array}$ & $\begin{array}{r}.44 \\
(6.1)\end{array}$ & $\begin{array}{c}.52 \\
(9.07)\end{array}$ & $\begin{array}{c}.51 \\
(8.88)\end{array}$ & $\begin{array}{r}.52 \\
(14.6)\end{array}$ & $\begin{array}{c}.14 \\
(1.02)\end{array}$ & $\begin{array}{c}.28 \\
(2.53)\end{array}$ & $\begin{array}{c}.16 \\
(1.18)\end{array}$ & $\begin{array}{c}.36 \\
(3.09)\end{array}$ & $\begin{array}{c}.39 \\
(18.18)\end{array}$ \\
\hline$W$ & $\begin{array}{c}-.06 \\
(-1.46)\end{array}$ & $\begin{array}{l}-.02 \\
(-.48)\end{array}$ & $\begin{array}{c}-.16 \\
(-3.2)\end{array}$ & $\begin{array}{c}.06 \\
(1.95)\end{array}$ & $\begin{array}{c}.12 \\
(1.89)\end{array}$ & $\begin{array}{c}.15 \\
(3.44)\end{array}$ & $\begin{array}{c}.19 \\
(2.86)\end{array}$ & $\begin{array}{c}.27 \\
(2.81)\end{array}$ & $\begin{array}{c}.14 \\
(1.62)\end{array}$ & $\begin{array}{c}.14 \\
(2.50)\end{array}$ & $\begin{array}{l}-.04 \\
(-.26)\end{array}$ & $\begin{array}{c}-.03 \\
(-0.22)\end{array}$ & $\begin{array}{c}-.21 \\
(-1.21)\end{array}$ & $\begin{array}{l}.00 \\
(.00)\end{array}$ & $\begin{array}{c}.04 \\
(1.59)\end{array}$ \\
\hline $\begin{array}{l}\text { Market } \\
\text { Malaysia }\end{array}$ & .04 & .07 & .03 & .09 & .09 & .06 & .15 & .05 & .11 & .08 & -.18 & .01 & -.09 & .05 & .04 \\
\hline$L$ & $\begin{array}{c}.37 \\
(2.05)\end{array}$ & $\begin{array}{l}-.1 \\
(-.49)\end{array}$ & $\begin{array}{l}-.1 \\
(-.93)\end{array}$ & $\begin{array}{c}.03 \\
(0.46)\end{array}$ & $\begin{array}{c}-.12 \\
(-1.92)\end{array}$ & $\begin{array}{l}-.03 \\
(-.16)\end{array}$ & $\begin{array}{r}.26 \\
(1.4)\end{array}$ & $\begin{array}{l}.13 \\
(.54)\end{array}$ & $\begin{array}{c}.26 \\
(2.39)\end{array}$ & $\begin{array}{c}.12 \\
(1.11)\end{array}$ & $\begin{array}{l}.11 \\
(.71)\end{array}$ & $\begin{array}{c}.19 \\
(1.99)\end{array}$ & $\begin{array}{c}.17 \\
(1.75)\end{array}$ & $\begin{array}{c}3.55 \\
(12.02)\end{array}$ & $\begin{array}{c}.35 \\
(4.07)\end{array}$ \\
\hline$W$ & $\begin{array}{c}1.04 \\
(7.31)\end{array}$ & $\begin{array}{c}.88 \\
(2.41)\end{array}$ & $\begin{array}{c}.4 \\
(1.98)\end{array}$ & $\begin{array}{c}.9 \\
(5.27)\end{array}$ & $\begin{array}{c}.32 \\
(1.95)\end{array}$ & $\begin{array}{l}.1 \\
(.35)\end{array}$ & $\begin{array}{l}-.15 \\
(-.61)\end{array}$ & $\begin{array}{l}.26 \\
(.73)\end{array}$ & $\begin{array}{c}.18 \\
(1.01)\end{array}$ & $\begin{array}{c}.92 \\
(5.37)\end{array}$ & $\begin{array}{c}.34 \\
(1.39)\end{array}$ & $\begin{array}{l}.11 \\
(.54)\end{array}$ & $\begin{array}{c}.22 \\
(1.23)\end{array}$ & $\begin{array}{c}.95 \\
(5.34)\end{array}$ & $\begin{array}{c}.46 \\
(6.73)\end{array}$ \\
\hline $\begin{array}{l}\text { Market } \\
\text { Taiwan }\end{array}$ & .23 & .06 & -.07 & .16 & -.1 & -.09 & .06 & .03 & .13 & .19 & -.03 & .05 & .08 & .34 & .07 \\
\hline$L$ & $\begin{array}{c}.09 \\
(1.53)\end{array}$ & $\begin{array}{l}.01 \\
(.29)\end{array}$ & $\begin{array}{c}-.24 \\
(-3.46)\end{array}$ & $\begin{array}{c}-.21 \\
(-2.05)\end{array}$ & $\begin{array}{c}-.19 \\
(-2.36)\end{array}$ & $\begin{array}{c}-.51 \\
(-4.44)\end{array}$ & $\begin{array}{c}-.24 \\
(-1.51)\end{array}$ & $\begin{array}{c}-.31 \\
(-1.38)\end{array}$ & $\begin{array}{c}-.44 \\
(-2.72)\end{array}$ & $\begin{array}{l}.07 \\
.4)\end{array}$ & $\begin{array}{c}-.7 \\
(-2.12)\end{array}$ & $\begin{array}{c}-.02 \\
(-0.19)\end{array}$ & $\begin{array}{c}-.22 \\
(-1.88)\end{array}$ & $\begin{array}{l}-.09 \\
(-.95)\end{array}$ & $\begin{array}{c}-.21 \\
(-4.94)\end{array}$ \\
\hline$W$ & $\begin{array}{c}.38 \\
(3.46)\end{array}$ & $\begin{array}{c}.25 \\
(2.54)\end{array}$ & $\begin{array}{c}.11 \\
(1.02)\end{array}$ & $\begin{array}{c}.29 \\
(2.13)\end{array}$ & $\begin{array}{c}.16 \\
(1.61)\end{array}$ & $\begin{array}{r}.36 \\
(2.9)\end{array}$ & $\begin{array}{c}.87 \\
(6.66)\end{array}$ & $\begin{array}{c}1.17 \\
(9.95)\end{array}$ & $\begin{array}{c}1.13 \\
(11.29)\end{array}$ & $\begin{array}{c}1.19 \\
(9.19)\end{array}$ & $\begin{array}{c}.76 \\
(4.41)\end{array}$ & $\begin{array}{c}.37 \\
(3.29)\end{array}$ & $\begin{array}{c}.26 \\
(2.29)\end{array}$ & $\begin{array}{c}.41 \\
(3.49)\end{array}$ & $\begin{array}{r}.55 \\
(12.83)\end{array}$ \\
\hline Market & .05 & .01 & -.05 & .17 & .07 & .02 & .08 & .31 & .29 & .2 & -.27 & .00 & -.11 & .2 & .07 \\
\hline
\end{tabular}


TABLE 7. (Continued)

\begin{tabular}{lcccccccccccccccc}
\hline & 1980 & 1981 & 1982 & 1983 & 1984 & 1985 & 1986 & 1987 & 1988 & 1989 & 1990 & 1991 & 1992 & 1993 & $80-93$ \\
\hline & $X$ & $X$ & $X$ & $X$ & $X$ & $X$ & $X$ & $X$ & $X$ & $X$ & $X$ & $X$ & $X$ & $X$ & $X$ \\
\hline \multirow{2}{*}{ Thailand } & & & & & & & & & & & & & & & \\
$L$ & -.34 & .15 & .32 & .01 & -.08 & -.03 & -.21 & -.34 & .02 & .23 & -.21 & .33 & .32 & .36 & .05 \\
& $(-4.17)$ & $(1.41)$ & $(4.67)$ & $(0.23)$ & $(-1.29)$ & $(-.23)$ & $(-1.61)$ & $(-1.04)$ & $(.2)$ & $(2.07)$ & $(-.87)$ & $(2.09)$ & $(2.79)$ & $(3.26)$ & $(1.09)$ \\
$W$ & .29 & .1 & .36 & .5 & .44 & .4 & .77 & 1.75 & .61 & 1.15 & .63 & .26 & .31 & .38 & .6 \\
& $(2.22)$ & $(1.65)$ & $(2.38)$ & $(6.15)$ & $(3.69)$ & $(2.66)$ & $(3.61)$ & $(6.4)$ & $(3.21)$ & $(5.44)$ & $(2.38)$ & $(1.31)$ & $(1.78)$ & $(2.12)(10.16)$ \\
Market & -.03 & -.01 & .11 & .09 & .07 & .01 & .22 & .16 & .14 & .36 & -.13 & .08 & .1 & .26 & .1 \\
\hline
\end{tabular}

Note: Yearly returns from a contrarian portfolio strategy based upon historical return data shown in equation (1). $L$ is the portfolio of loser stocks while $W$ is the portfolio of winner stocks. $X$ is the mean return, and the $t$-stat is the Newey-West $t$-statistic, which corrects for heteroscedasticity and autocorrelation problems. The final column reflects the average of yearly returns and coincides with Table 1 results. The market indices reflect the performance of the valueweighted portfolios of each national market and are included for comparative purposes. 
The results across years show that winner portfolios consistently provide strong, positive returns while loser portfolios yield lower returns with some strongly negative. These results suggest that a contrarian trading strategy would not be profitable in most of these markets. Japan is the exception among the Asian markets and shows a return pattern similar to that of the U.S. market. Studies show that national markets have different characteristics that may affect return behavior, ${ }^{16}$ and size is an important characteristic that distinguishes Japan and the U.S. from the other markets in the study. Japan and the U.S. are the world's two largest equity markets where institutional investors have directed much of their attention during the years covered by this paper. This study focuses upon return behavior in Pacific Basin markets but does not preclude the probability that market size may be a more significant variable than geography. Our yearly results from the U.S. market are consistent with other contrarian studies with winner portfolios producing negative returns and loser portfolios yielding positive returns. Interestingly, the yearly performances from Asia suggest that a momentum strategy may be more appropriate for most of these markets, a finding similar to the Rouwenhorst (1998) study of European markets that are of comparable size to those in our study.

\section{Conclusion}

This article examines a short-term trading strategy to determine if profitable trading strategies of U.S. stocks may be applied successfully to six Pacific Basin markets. The result indicates striking differences in the behavior of short-term portfolio returns between the U.S. and most Asian markets. Price reversal behavior is observed quite strongly in U.S. stocks and is found to a lesser extent in Japanese stocks. Thus, a contrarian trading strategy would have its greatest success in these markets. The remaining Pacific Basin markets exhibit return behavior that may be more profitably exploited by other trading strategies that emphasize momentum effects. Profits from daily portfolio construction are virtually eliminated when transaction costs are included, suggesting that longer holding periods and higher filters should be implemented in trading strategies. Importantly, the study reveals that different return behavior exists across national markets so that profitable trading

16. See Lo et al.(1993) and Rhee and Chang (1992). 
strategies in the U.S. markets may not prove universally successful.

The similar profit results in terms of size and direction of return movement for different filtering rules and longer holding-period horizons suggest that these profits result primarily from true return behavior and not from biases caused by a bid-ask bounce. Thus, these results produce reliable evidence that stylized trading rules may produce profit opportunities in Pacific Basin markets.

The results indicate that trading volume provides important information to the portfolio construction process in all the markets. Additionally, a nonlinear returns-based methodology and the return size-based rule are shown to enhance profit opportunities. These results imply that information in volume and nonlinearity in returns may be exploited to improve trading profits.

An important contribution of this article is that it identifies significant differences in return behavior that exist across markets. While the patterns in return behavior may be interpreted as investor over- or underreaction, it is quite probable that the size differential between the Japanese and U.S. markets and the other national markets proxies for the variables that contribute to the different return behaviors across markets. The variation in market sizes may reflect differences in the speed and breadth of information flow to the investment community. Additionally, the roles played by institutional and individual investors differ across markets, and their responses to information flows may produce different patterns in return behavior. While providing a definitive answer for such differences is beyond the scope of this article, future research on return behavior may focus on structural differences that exist across markets.

\section{References}

Bailey, W.; R.M. Stulz; and S. Yen. 1990. Properties of daily stock returns from the Pacific Basin stock markets: Evidence and implications. Pacific Basin Capital Markets. S.G. Rhee and R. Chang (eds.), New York: North Holland.

Ball, R.; S.P. Kothari; and C.E. Wasley. 1995. Can we implement research on stock trading rules? Journal of Portfolio Management 21, 54-63.

Berkowitz, S.A.; D.E. Logue; and E.A. Noser. 1988. The total cost of transactions on the NYSE. Journal of Finance 43, 97-112.

Bernard, V., and J. Thomas. 1990. Evidence that stock prices do not fully reflect the implications of current earnings for future earnings. Journal of 
Accounting and Economics 13, 305-341.

Blume, L.; D. Easley; and M. O'Hara. 1994. Market statistics and technical Analysis: The role of volume. Journal of Finance 49, 153-181.

Brown, K.; W. Harlow; and S. Tinic. 1988. Risk aversion, uncertain information, and market efficiency. Journal of Financial Economics 22, 355-385.

Campbell, J.Y.; S.J. Grossman; and J. Wang. 1993. Trading volume and serial correlation in stock returns. Quarterly Journal of Economics 108, 905-940.

Chan, L.K.; N. Jegadeesh; and J. Lakonishok. 1996. Momentum strategies. Journal of Finance 51, 1681-1713.

Chan, L.K., and J. Lakonishok. 1997. Institutional equity trading costs: NYSE versus Nasdaq. Journal of Finance 52, 713-735.

Chan, L.K., and J. Lakonishok. 1995. The behavior of stock prices around institutional trades. Journal of Finance 50, 1147-1174.

Conrad, J.S.; M. Gultekin; and G. Kaul. 1997. Profitability of short-term contrarian strategies: Implications for market efficiency strategies. Journal of Business and Economic Statistics 15, 3, 379-386.

Conrad, J.S.; A. Hameed; and C. Niden. 1994. Volume and autocovariances in short-horizon individual returns. Journal of Finance 49, 1305-1329.

Conrad, J.S.; G. Kaul; and M. Nimalendran. 1991. Components of shorthorizon individual security returns. Journal of Financial Economics 29, 365-384.

Corrado C. and S. Lee. 1992. Filter rule tests of the economic significance of serial dependencies in daily stock returns. The Journal of Financial Research 15, 369-387.

Cox, D. and D. Peterson. 1994. Stock returns following large one-day declines: Evidence on short-term reversals and longer-term performance. Journal of Finance 49, 255-267.

DeBondt, W. and R. Thaler. 1985. Does the stock market overreact? Journal of Finance 40, 793-805.

Fama, E.F. and M.E. Blume. 1966. Filter rules and stock-market trading. Journal of Business 39, 226-241.

Grinblatt, M.; S. Titman; and R. Wermers. 1995. Momentum investment strategies, portfolio performance, and herding: A study of mutual fund behavior. American Economic Review 85, 1088-1105.

Jones, C.M.; G. Kaul; and M.L. Lipson. 1994. Transactions, volume and volatility. Review of Financial Studies 4, 543-569.

Karpoff, J.M. 1987. The relation between price changes and trading volume: A survey. Journal of Quantitative and Financial Analysis 22, 109-126.

Lehmann, R.. 1990. Fads, martingales, and market efficiency. Quarterly Journal of Economics 105, 1-28.

Lo, A., and C. MacKinlay. 1988. Stock market prices do not follow random walks: Evidence from a simple specification test. Review of Financial Studies 1, 41-66. 
Lo, A., and C. MacKinlay. 1990. When are contrarian profits due to stock market overreaction? Review of Financial Studies 3, 175-205.

Lo, W.C.; H.G. Fung; S.K. Chen; and G.C. Lai. 1993. Dependency in Pacific Basin stock returns. International Review of Financial Analysis 3, 199-210.

Rhee, S.G., and R.P. Chang. 1992. The microstructure of Asia equity markets. Journal of Financial Services Research 6, 437-445.

Rouwenhorst, K.G. 1998. International momentum strategies. Journal of Finance 53, 267-284. 